\title{
研磨引起的 $\mathrm{Bi}_{8} \mathrm{SrCaO}_{14}$ 晶体到非晶的转变
}

\author{
钱逐泰 迅习清 陈祖耀 \\ (中国科学支术大学应用化学系,合肥 230026)
}

周贵恩 馀 晨 黄允兰 范成高

(中国科学支术大学结构成分分析中心，合肥 230026)

关镜词 $\mathrm{Bi}_{8} \mathrm{SrCaO}_{14}$ 晶体、研磨、非晶、转变

Tsuneyuki Kanai 等发现机械研磨能引起样品 $\mathrm{Bi}-\mathrm{Pb}-\mathrm{Sr}-\mathrm{Ca}-\mathrm{Cu}-\mathrm{O}$ 超导临界温度 $T_{\mathrm{c}}$ 的 佭低和物相的改变 ${ }^{[1]}$, 当研磨时间从两分钟逐渐增加时, 在 $\mathrm{X}$ 射线粉末行射图中对应于高 $T_{\mathrm{c}}$ 的 2223 相 $\left(T_{\mathrm{c}}-107 \mathrm{~K}\right)$ 的峰的强度逐渐减弱, 峰宽逐步增宽, 最后到六十二分钟时变成非超 导的相, 从 X 射线粉末衍射图来看几乎为无定形相, 这种现象可能与结构中 Bi-O 双层密切相 关. 因为相对于其它部分, $\mathrm{Bi}-\mathrm{O}$ 双层间距离 $(3.1-3.2 \AA)$ 较大, 意味着结合力薄弱. 为了进 一步了解这种现象, 我们研究了 $\mathrm{Bi}-\mathrm{Sr}-\mathrm{Ca}_{2}-\mathrm{O}$ 晶体, 并且在室温下在玛瑙研钭中对 $\mathrm{Bi}_{8} \mathrm{SrC}_{\mathrm{C}} \mathrm{O}$ 晶体进行了研磨, 结果发现这种晶体更容易被磨成非晶. 但如果在酒精或水中研磨, 则会象在 通常情况下一样变成多晶. 这一结果被多次实验所重复.

$\mathrm{Bi}_{8} \mathrm{SrC}_{2} \mathrm{O}_{14}$ 晶体是在 $\mathrm{Bi}-\mathrm{Sr}-\mathrm{C}_{2}-\mathrm{Cu}-\mathrm{O}$ 单晶生长过程中挑选出来的非超导的小单晶, 样品呈 黄色、半透明、片状, 一般大小为 $6 \times 4 \times 0.1 \mathrm{~mm}^{3}$. 用 $\mathrm{H}-800$ 型透射电子显微镜的能量损失橧 (EDS) 对样品进行成分分析, 得到该晶体的化学式为 $\mathrm{Bi}_{8} \mathrm{SrCaO}_{14}$. 用丹东仪器厂制造的 $\mathrm{JF}-14$ 型 $\mathrm{X}$ 射线晶体分析仪做此晶体的劳埃图, 结果表明晶体为三方晶格(图 1). 用日本理学 $\mathrm{D} /$

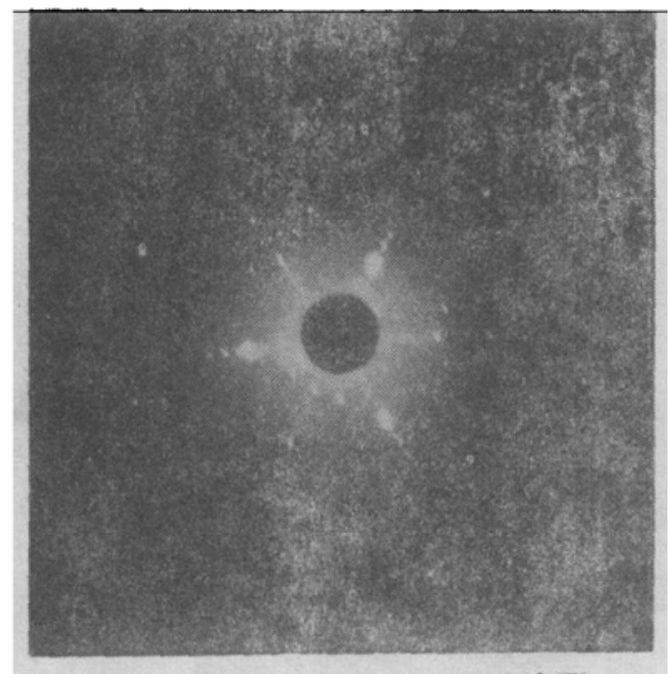

国 1 单昆 $\mathrm{Bi}_{8} \mathrm{SrCaO}_{14}$ 的学埃图

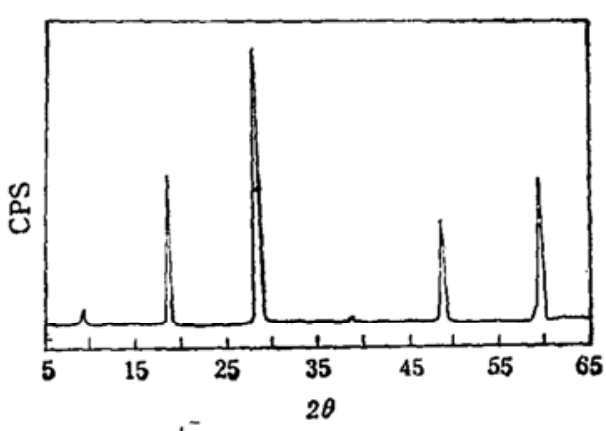

图 2 单晶 $\mathrm{Bi}_{8} \mathrm{SrC}_{2} \mathrm{O}_{14}$ 的 $(001)$ 晶面 多级衍射图

本文 1990 年 12 月 23 日收到. 1991 年 11 月 6 日收到修改稿.

第 7 期

科学通

报 
MAX-rA 转轮 X 射线衍射仪做它的 (O0L) 晶面多级衍射图(图 2). 如取六方定向, 从此圈上 可以得知格子常数 $c$ 约为 $9.504 \AA$ 的倍数, 而且无其它的 $00 \mathrm{~L}$ 峰, 由于 $\mathrm{X}$ 光斑点为 $0.5 \times 0.5 \mathrm{~cm}^{2}$, 因此可见整个晶体中没有杂质相.

若把小晶体在酒精或水中进行湿磨, X 射线粉末衍射图中 00L 峰较强(图 3), 这表明辟 品为具有 $(00 \mathrm{~L})$ 择优取向的多晶. 从图 3 可以计算出三方格子常数为: $a-9.776 \AA, a=$ $23.41^{\circ}$. 如选取六方定向, 其格子常数则可定为 $a=3.967 \AA, c-28.512 \AA$. 这与文献报道 的 $\mathrm{Bi}-\mathrm{Sr}-\mathrm{O}$ 或 $\mathrm{Bi}-\mathrm{Ca}-\mathrm{O} \equiv$ 方相的格子常数十分接近 ${ }^{[2,3]}$. 因此可以认为,这个新三方相是介 于 $\mathrm{Bi}-\mathrm{Sr}-\mathrm{O}$ 和 $\mathrm{Bi}-\mathrm{Ca}-\mathrm{O}$ 的某种固熔体.

图 4 为分别把 $50 \mathrm{mg}$ 晶体干磨 $1 、 4 、 8 、 12 \mathrm{~min}$ 后的 $\mathrm{X}$ 射线粉末衍射图. 图 4(a) 是干磨 $1 \mathrm{~min}$ 的情况: 009 峰强,图中所有的峰都可用上述的三方格子常数指标. 随着研磨时间的逐 渐增加, 对应于三方相的峰的强度不断减弱. 当研磨时间超过 $12 \mathrm{~min}$ 时, $\mathrm{X}$ 射线粉末衍射图 上仅在 $2 \theta-30^{\circ}$ 附近有一个平坦的宽蜂,这表明了非晶的形成.

使用 $\mathrm{H}-800$ 型透射电子显微镜进行形态观察, 并拍摄其电子衍射图像. 加速电压为 $200 \mathrm{kV}$. 对于干磨 $12 \mathrm{~min}$ 后的样品, 电子显微镜观察不到清晰的颗粒. 相应的电子衍射图 给出了作为非晶特征的晕环而无德拜(Debye)行射环或斑点(图 5a、5b). 相反, 对于酒情中湿 磨的样品, 电子显微镜可以观察到清晰的小晶体形貌(图 6a). 电子衍射法得出小晶体具有六 方的衍射花样(图 6b). 这些结果都与 $X$ 射线粉末衍射法所得的结果相一致.

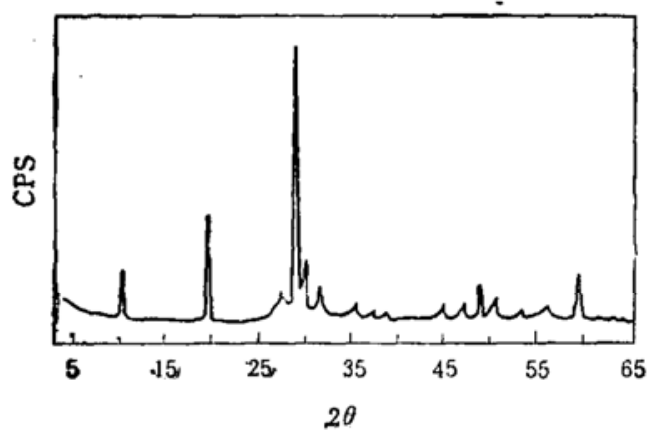

图 3 湿磨 $\mathrm{Bi}_{8} \mathrm{SrCaO}_{1}$ 晶体的 $\mathrm{X}$ 射线 粉末衍射图

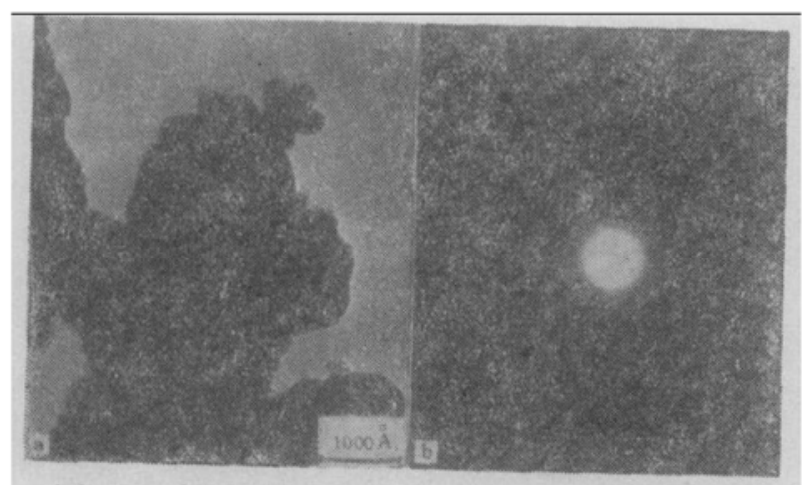

图 5 千層样品 $\mathrm{Bi}_{8} \mathrm{SrCaO}_{14}$ 的形貌照片(a)和 电子衍射花样(b)

610

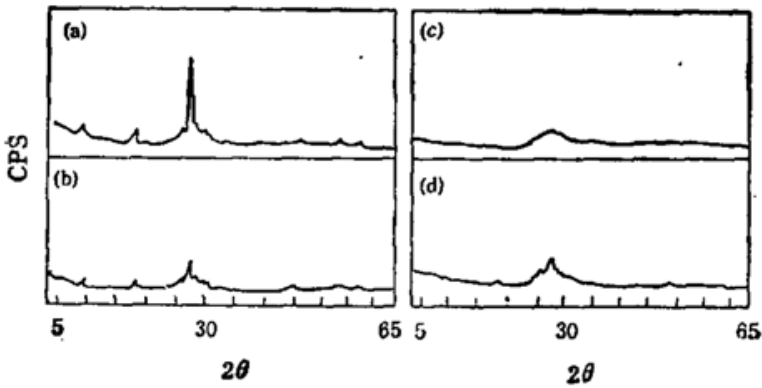

图 4 不同时间干客 $\mathrm{Bi}_{8} \mathrm{SrC}_{2} \mathrm{O}_{14}$ 晶体的 $\mathrm{X}$ 射线粉末衍射图

(a) $1 \mathrm{~min}$; (b) $4 \mathrm{~min}$; (c) $8 \mathrm{~min}$; (d) $12 \min$

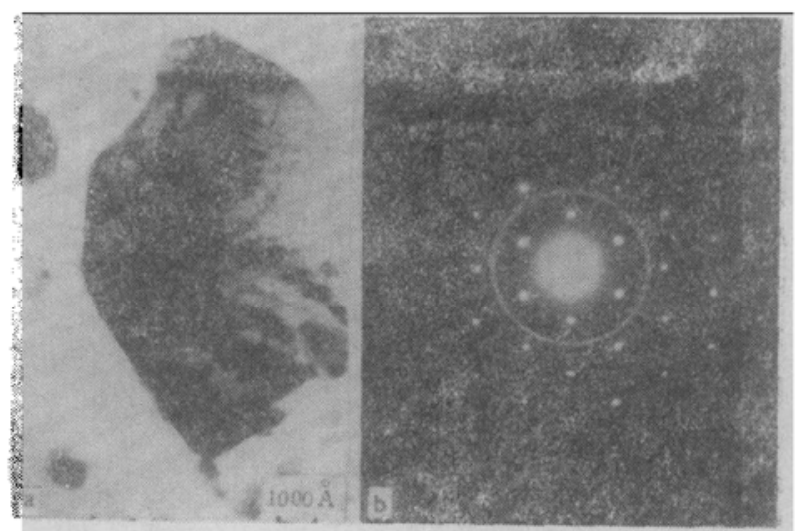

图 6 湿磨样品 $\mathrm{Bi}_{8} \mathrm{SrCaO}_{14}$ 的形貌照片 (a) 和 电子行射花样(b)

1992 年 
Conflat. 等对 $\mathrm{Bi}_{0.765} \mathrm{Sr}_{0.235} \mathrm{O}_{1.383}$ 的结构进行了描述和研究 ${ }^{[4]}$, 指出 $\mathrm{Bi}-\mathrm{Sr}-\mathrm{O}$ 其有层状缩沟, 其空间群为 $\mathrm{R} \overrightarrow{3} \mathrm{~m}, a-9.75 \AA, \alpha-23.49^{\circ}$. 由于此结晶学数据与 $\mathrm{Bi}_{8} \mathrm{SrCaO}_{14}$ 的 $(a=9.776 \AA$, $\left.\boldsymbol{a}=23.41^{\circ}\right)$ 相近, 我们可以认为它们结构也相似. 三维结构可以描述为二维的 $\mathrm{Bi}-\mathrm{M}-\mathrm{O}$ 六 边形沿三次反轴方向堆砌, 层间距为 3.1-3.49 , 层间几乎只有范德华键. 湿磨时与云) 㥵 似形成(001)择优取向的多晶. 这可能是因为湿磨时由于摩擦所产生的热被介质吸收. 让云 母中 $\mathrm{Si}-\mathrm{O}$ 键较强, $\mathrm{Bi}_{8} \mathrm{SrCaO}_{14}$ 中主要的键为 $\mathrm{Bi}-\mathrm{O}$ 键, $\mathrm{Bi}-\mathrm{O}$ 键较弱: 键能 $\mathrm{D}_{298}^{\circ}(\mathrm{Bi}-\mathrm{O})=$ $342.7 \pm 5.9(\mathrm{~kJ} / \mathrm{mol}), D_{298}^{\circ}(\mathrm{Si}-\mathrm{O})=798.7 \pm 8.4(\mathrm{~kJ} / \mathrm{mol})^{[9]}$. 所以干磨就可能不但使晶依沿 (001) 面分裂, 而且压力和热量的合效应还能使 $\mathrm{Bi}-\mathrm{O}$ 键断裂, 导致晶体到非晶的转变. 以上 结果也从侧面证实超导 2223 相经一小时后研磨而向非晶化转变与 $\mathrm{Bi}-\mathrm{O}$ 层有关.

\section{参考文献}

[1] Tsuneyuki Kanai et al., Japan J. of Applied Phys., 29(1990), 412-415.

[2] Aurivillius, B., Arkiv Kemi Mineral. Geol., Al6(1943), 1-13.

[3] Levin, E. M. and Roth, R. S., J. Res. Natl. Bur. Std., A68(1964), 197-206.

[4] Conflant, P., Boivin, J. C. and Thomas, D., J. Solid State Chem., 35(1980), $192 \cdots 199$.

[5] Weast, R. C., in Handbook of Chem. and Phys., 62nd ed., CRC Press, Florida,1981: 